\title{
Compressive, flexural and abrasive performances of steel fiber reinforced concrete elements
}

\author{
B. Setti ${ }^{1}$, M. Taazount ${ }^{2, *}$, S. Hammoudi ${ }^{1}$, F. Setti ${ }^{1}$, M. Achit-Henni ${ }^{1}$ \\ ${ }^{1}$ Laboratoire Sciences Des Matériaux et Environnement, Département de Génie Civil, Université de Chlef, BP 151 Chlef RP, Algeria \\ ${ }^{2}$ Institut Pascal ; Polytech'Clermont-Ferrand, 24 Avenue Des Landais, BP 206, 63174 Aubière, France
}

\section{Email address:}

setti_b@yahoo.fr(B. Setti), mustapha.taazount@univ-bpclermont.fr(M. Taazount), achithm@yahoo.fr(M. Achit-Henni)

\section{To cite this article:}

B. Setti, M. Taazount, S. Hammoudi, F. Setti, M. Achit-Henni. Compressive, Flexural and Abrasive Performances of Steel Fiber Reinforced Concrete Elements. International Journal of Mechanical Engineering and Applications. Vol. 1, No. 3, 2013, pp. 69-77. doi: $10.11648 /$ j.ijmea.20130103.12

\begin{abstract}
Concrete brittle fracture and low tensile strength constitute an important durability problem, since they can lead to disastrous damage and failure of the reinforced concrete structures. The improvement of concrete mechanical properties by adding steel fibers to plain concrete is considered as an interesting solution to the problem. This work fits into the continuity of scientific contributions in the field of Steel Fiber Reinforcement Concrete (SFRC). It relies on an experimental study conducted to examine compressive, flexural and abrasion resistance of steel fiber reinforced concrete specimens. The used Steel Fibers (S.F) are curved steel elements with a length to diameter ratio equal to 67. Concrete is made of local materials. The steel fiber contents examined are $0.5 \%, 1 \%$ and $1.5 \%$. The purpose of this research is to investigate the mechanical performances of steel fibers reinforced concrete regarding compressive strength, flexural strength, mechanical abrasion and ductility according to the specimen age. The experimental results show a significant improvement in the mechanical behavior of the SFRC specimens in comparison with plain concrete without reinforcement.
\end{abstract}

Keywords: Steel Fiber Reinforcement, Compressive Strength, Flexural Strength, Abrasion Weight Loss

\section{Introduction}

Concrete, because of its low cost and constant technological progress, is the most widely used material in civil engineering construction. However, its low tensile strength, its fragility and its predisposition onto micro cracking limit its use to compressed areas. When used instructures subjected to tensile stresses, some reinforcement elements, usually steel bars, are needed. An alternative technique, consisting in the addition of steel fibers (SF) to concrete, is an effective way of replacing classical reinforced concrete. The strengthening of concrete with SF improves the mechanical behavior of concrete elements; delays crack initiation and increase the ductility to hinder brittle fracture [1]. The compressive strength of cylindrical specimens made of plain concrete is generally characterized by the appearance of breakdown points with formation of shear lines and compressive cone or spalling. The presence of SF in concrete enhances the compressive strength and the ductility of the material.

When compressed, steel fibers tend to buckle quickly. However, they contribute to prevent concrete swelling and bursting through adhesion and shearing strength. Steel fibers, indeed, can increase the adhesion between the different components of the SFRC material matrix. Many studies have shown that the addition of SF to concrete increases the compressive strength by approximately $10 \%$ to $20 \%$ compared with ordinary concrete $[2,3,4,5]$. Some specific studies also highlight these properties $[6,7,8]$. Moreover, for a SF volumetric content of $1.5 \%$, the static resistance after 28 days of compression fracture increases by $35 \%$ [9] and by $21.2 \%$ for a SF content of $2 \%$ [10].

Steel Fiber Reinforced Concrete (SFRC) mechanical relevance is certainly increased in the case of specimens submitted to flexural and tensile loads. Under loading, the steel fibers are then subjected to pulling forces but their adhesion to concrete acts as crack inhibitor and increases the global resistance of the specimen [11, 12, 13, and 14]. On a microscopic scale, the SF reinforcement is often complex and depends on the microstructure the added fibers have created [15]. Moreover, the geometrical and mechanical characteristics of steel fibers change depending on the fiber type. Consequently, each SF type affects the mechanical behavior of SFRC elements differently. The choice of fibers type depends on both the application scope 
and the mechanical properties desired [16]. Bending tests are often carried out on laboratory specimens and real beams [17]. Mechanical results are obtained using force and displacement (stress/strain) control. The mechanical ductility depends not only on the SF type content and orientation but also on the nature of the deformation. Steel fibers with bent ends are better than fully bent fibers because of the mechanical anchor they induce [18]. Among these, hooked-end fibers are best because of the good mechanical grip they offer [19].

Concrete is used to build civil engineering structures, which may be affected by mechanical friction when concrete comes in contact with water. The abrasion resistance is one key consideration of technical design. Surface wear caused by abrasion and erosion contributes to the reduction of concrete durability [20]. Abrasion due to traffic particularly affects industrial floors, sidewalks and roadways [21]. The addition of SF to concrete increases the abrasion resistance, which is directly influenced by the material compressive strength [22]. SFRC specimens with volumetric contents of $0.5 \%$ and $1 \%$ can reduce the mechanical wear by $2 \%$ to $9 \%$, respectively [23]. SFRC is distinguished by its ability to absorb and dissipate energy, reduce the initiation and propagation of cracks, increase the durability of concrete subjected to abrasion and slow the degradation of the material.

This study comes within the continuation of scientific investigations conducted yet not far enough, to examine concrete, to whom steel fibers are added in order to improve compression, bending and abrasion resistance. Classical $16 \times 32$ (diameter $=16 \mathrm{~cm}$, height $=32 \mathrm{~cm}$ ) cylindrical specimens are used for compression testing. Prismatic $7 \times 7 \times 28 \mathrm{~cm}^{3}$ specimens are used for the three-point bending tests. $7 \times 7 \times 14 \mathrm{~cm}^{3}$ specimensare used for "MicroDuval" Los Angeles abrasion testing. The SF contents of the test specimens are different. Concrete mix contains local materials from Chlef (Algeria) currently used in actual concrete structures. The objective of this study is the description of SFRC mechanical performances and the quantification of its beneficial changes, in comparison with plain concrete, as a function of SF volumetric content. The adopted steel fiber percentages by volume are $0.5 \%, 1 \%$ and $1.5 \%$, respectively. Three specimens are made for each test series. First results confirm those found in the literature and are used to propose a behavioral mathematical approach.

\section{Material Characteristics}

The materials used are of local origin and commonly used for concrete building structures. The cement is a CPJCEM II/A42.5 type material with a density of3.1 and a specific surface area of $3700 \mathrm{~cm}^{2} / \mathrm{g}$. Its chemical and mineralogical characteristics are presented in Table 1.

Table 1: Cement composition (\%).

\begin{tabular}{|c|c|c|c|c|c|c|c|c|}
\hline \multirow{2}{*}{$\begin{array}{c}\text { Chemical composition } \\
(\%)\end{array}$} & $\mathrm{SiO}_{2}$ & $\mathbf{A l}_{2} \mathbf{O}_{3}$ & $\mathrm{Fe}_{2} \mathrm{O}_{3}$ & $\mathrm{CaO}$ & $\mathrm{SO}_{3}$ & MgO & $\mathbf{K}_{2} \mathbf{O}$ & PAF \\
\hline & 20.58 & 4.90 & 4.70 & 62.8 & 2.28 & 0.63 & 0.42 & 1.00 \\
\hline \multirow{2}{*}{$\begin{array}{l}\text { Mineralogical composition } \\
\text { (\%) }\end{array}$} & \multicolumn{2}{|r|}{$\mathrm{C}_{3} \mathrm{~S}$} & \multicolumn{2}{|r|}{$\mathrm{C}_{2} \mathrm{~S}$} & & $\mathrm{C}_{3} \mathrm{~A}$ & \multicolumn{2}{|r|}{$\mathrm{C}_{4} \mathrm{AF}$} \\
\hline & \multicolumn{2}{|r|}{41.8} & \multicolumn{2}{|r|}{33.3} & & 5.1 & & 10.7 \\
\hline \multirow{2}{*}{$\begin{array}{c}\text { Cement composition } \\
\text { (\%) }\end{array}$} & \multicolumn{3}{|c|}{ Clinker } & \multicolumn{3}{|c|}{ Calcareous } & \multicolumn{2}{|c|}{ Gypsum } \\
\hline & \multicolumn{3}{|c|}{86.5} & \multicolumn{3}{|c|}{10} & \multicolumn{2}{|c|}{3.5} \\
\hline
\end{tabular}

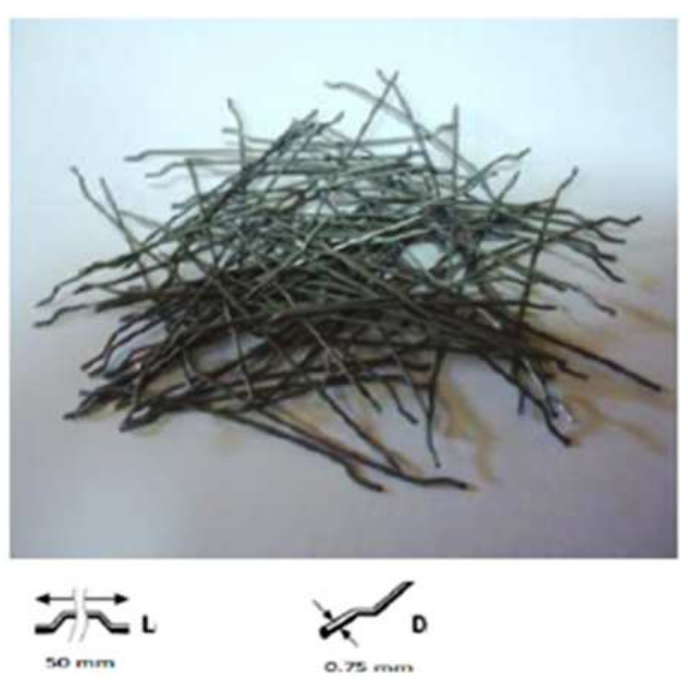

Figure 1: «HE++ 75/50»Steel Fibers.
Sand is river sand with a specific gravity of 1.63 , a fineness modulus, $\mathrm{M}_{\mathrm{f}} \mathrm{of} 2.42$ and a sand equivalent, $\mathrm{E}_{\mathrm{s}}$, of 89.74.Gravels are crushed aggregates $(<10 \mathrm{~mm})$ with an impurity content of approximately $1.2 \%$ and a Los Angeles coefficient $\mathrm{L}_{\mathrm{A}}=24 \%$. To control concrete workability and keep the same consistency while introducing steel fibers, a super-plasticizer« MEDAFLOW $30 »$ type is added. This yellowished-colored super-plasticizer is a high range water reducer with a density of 1.07.Tap water is used with a conventional considered density of $1000 \mathrm{~kg} / \mathrm{m}^{3}$. «HE++ $75 / 50$ » type hooked-ends steel fibers $50 \mathrm{~mm}$ in length and a diameter of $0.79 \mathrm{~mm}$ are used. They have a tensile strength of $1.9 \mathrm{Gpa}$ and a geometrical ratio of $\left(\mathrm{l}_{\mathrm{f}} / \mathrm{d}_{\mathrm{f}}=67\right)$ (Fig 1).

The super-plasticizer content increases with the SF volumetric content. Tested SF concentrations by volume are $0 \%, 0.5 \%, 1 \%$ and $1.5 \%$, respectively. For a homogeneous distribution of the SF during mixing, SF are 
introduced at the end of the process, after water and superplasticizer are added. Concrete mix design variables are presented in Table 2.

$16 \times 32$ cylindrical and $7 \times 7 \times 28 \mathrm{~cm}^{3}$ prismatic specimens are cast. The specimens are compacted by means of vibration methods. All specimens are demoulded after 1 day and cured into water until test. Curing temperature is $20^{\circ} \mathrm{C} \pm 2{ }^{\circ} \mathrm{C}$. Three SF specimens and three specimens of plain concrete (non-SFRC) used as control samples are cast for each mechanical test series. Strength and deformation measurements are carried out using a Control $3000 \mathrm{KN}$ hydraulic press and displacement sensors with a $10^{-3}-\mathrm{mm}$ uncertainty of measurement.

Table 2: Concrete composition $(\mathrm{kg} / \mathrm{m} 3)$

\begin{tabular}{|c|c|c|c|c|c|c|c|c|}
\hline Concrete & $\begin{array}{l}\text { Sand } \\
\text { (kg) }\end{array}$ & $\begin{array}{l}\text { Aggregate } \\
\text { (kg) }\end{array}$ & $\begin{array}{l}\text { Cement } \\
\text { (kg) }\end{array}$ & $\begin{array}{l}\text { Water } \\
\text { (l) }\end{array}$ & $\mathbf{W} / \mathbf{C}$ & $\begin{array}{l}\text { Adjuvant } \\
(\%)\end{array}$ & $\begin{array}{l}\text { Steel Fiber } \\
\text { (kg) }\end{array}$ & $\begin{array}{l}\text { Subsidence } \\
\text { (cm) }\end{array}$ \\
\hline $\begin{array}{l}\text { SFRC_0 } \\
(0 \%)\end{array}$ & 750 & 1058 & 400 & 180 & 0.45 & 1 & 0 & 8 \\
\hline $\begin{array}{l}\text { SFRC_0.5 } \\
(0.5 \%)\end{array}$ & 750 & 1045 & 400 & 180 & 0.45 & 1,5 & 39 & 6 \\
\hline $\begin{array}{l}\text { SFRC_1 } \\
(1 \%)\end{array}$ & 750 & 1031.7 & 400 & 180 & 0.45 & 2 & 78 & 9 \\
\hline $\begin{array}{l}\text { SFRC_1.5 } \\
(1.5 \%)\end{array}$ & 750 & 1017.8 & 400 & 180 & 0.45 & 2.5 & 117 & 10 \\
\hline
\end{tabular}

\section{Experimental Program}

\subsection{Compression and Flexion Tests}

The compression test (Fig.2) is performed in accordance with «NF EN 1239-1 » and «NF EN 1239-3 » European standards $[24,25]$.The $16 \times 32$ cylindrical specimens are used for determining concrete compressive strength at different ages and for different SF volumetric contents. A uniform rate of loading of $14(\mathrm{MPa} / \mathrm{min})$ is applied on the specimen until failure. The maximum load is recorded. The compressive strength is obtained using the classical

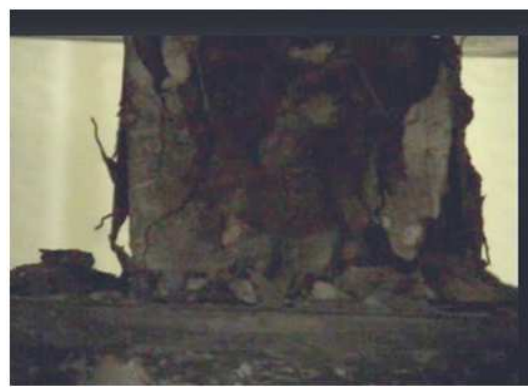

Figure 2: Compression tests.

The three-point bending test (Fig.3) is carried out in accordance with "NF EN 12390-5" standard [26, 27] oncubic $7 \times 7 \times 28 \mathrm{~cm}^{3}$ specimens. An increasing load is applied at mid-span of the specimens with a constant loading rate of $0.25( \pm 0.03) \mathrm{mm} / \mathrm{min}$ until failure [26]. Load and displacement measurements are recorded instantaneously. The deflection value corresponding to first crack loading is recorded. The maximum load is measured and the flexural strength is given by (2):

$$
\sigma_{m}=\frac{3}{2} \frac{F l}{b^{3}}
$$

where $\mathrm{F}$ is the ultimate load, 1 is the distance between both support points and $\mathrm{b}$ is the thickness. formula(1):

$$
\sigma_{c}=\frac{F}{A_{c}}
$$

where $\mathrm{F}$ is the maximum load and $\mathrm{A}_{\mathrm{c}}$ the area of the specimen, on which the load is applied. For each SF content $(0 \%, 0.5 \%, 1 \%$ and $1.5 \%)$, three tests are carried out and the mean value is calculated from the three single values obtained for different concrete ages $(1,3,7,28$, and 90 days).

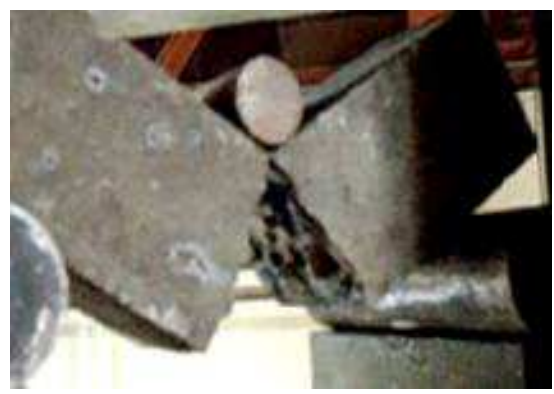

Figure 3: Flexion tests.

\subsection{Abrasion Tests}

The abrasion tests are carried out on $7 \times 7 \times 14 \mathrm{~cm}^{3}$ specimens with approximately the same weight. These smaller specimens are obtained from thecubic $7 \times 7 \times 28 \mathrm{~cm}^{3}$ specimens fabricated for the bending tests. A high performance chainsaw is used for sample cutting and preparation (Fig.4). The specimens are then introduced into the "micro-Duval" abrasion-testing machine (Fig.5). In each compartment of the device, we place: three concrete prisms (weight $=1.2$ to $1.5 \mathrm{~kg}$ ), 3 sphericalstainless steel balls (diameter $=47 \pm 1 \mathrm{~mm}$, weight $=420$ to $445 \mathrm{~g}$ ), $1.5 \mathrm{~kg}$ of small spherical stainless steel balls $(\mathrm{D}=10 \pm 0.5 \mathrm{~mm})$ and 2.5 liters of water. 


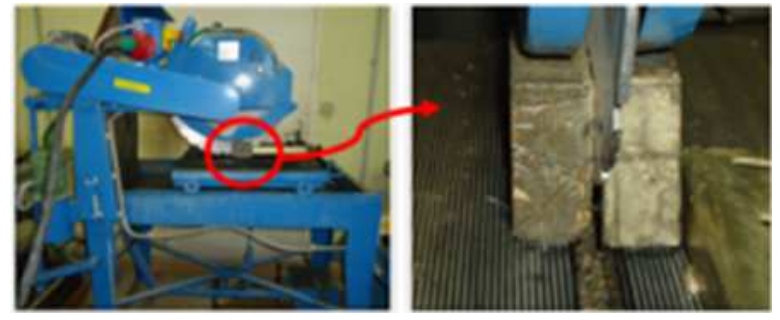

Figure 4: Chainsawfor sample cutting and preparation.

The specimens are subjected to 12000rotationsper2 hours at a constant speed of $100 \pm 5 \mathrm{rev} / \mathrm{min}$. At the end of the test, the specimens are washed, dried in the oven and weighed. The difference in weight before and after abrasion testing reveals the specimen mass losses for the different SF contents according to abrasion time (2, 4, 6, and 8 hours).

\section{Mechanical Test Results and Discussions}

All the mechanical measurements used to study the effects of the addition of steel fibers to concrete mixes are compared with those obtained with a control plain concrete specimen prepared under the same conditions (non-SFRC specimen).The results considered for each variable

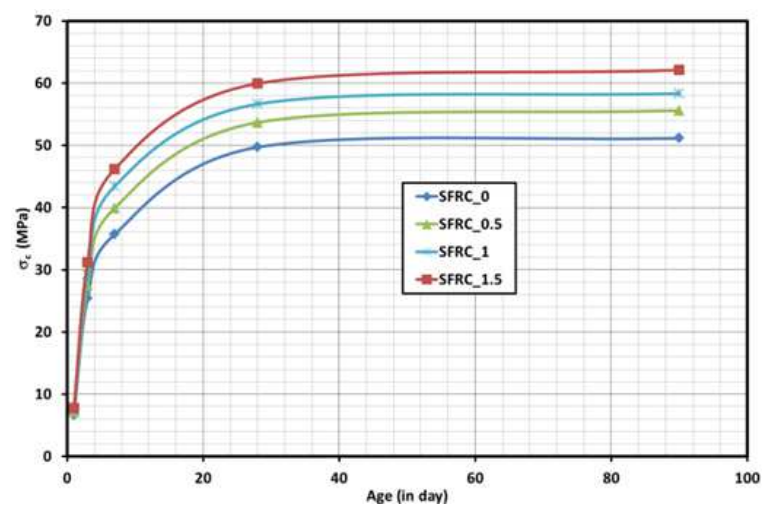

Figure 6: Compressive stress - age (day) evolutions.

The same trend is also observed at 28 and 90 days of age. Moreover, at 28 and 90 days of age, the stabilization observed in the resistance increase is, about $9 \%, 14 \%$ and $21 \%$ for the SF contents of $0.5 \%, 1 \%$ and $1.5 \%$, respectively (Fig.8). These results satisfactorily agree with those found in the literature $[28,29,30]$. The small

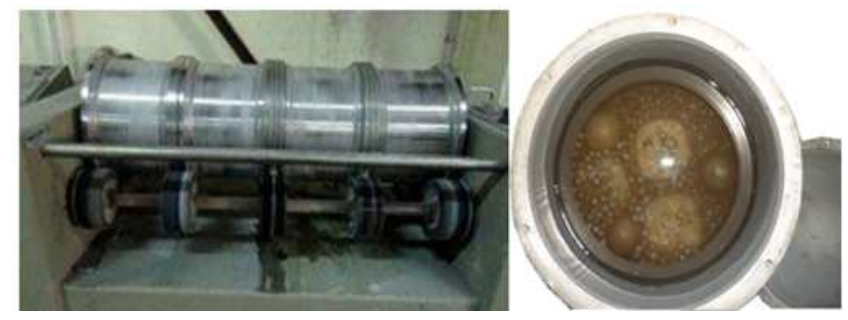

Figure 5: Abrasion testing machine.

represent the mean value calculated from three single measurements.

\subsection{Compressive Strength}

Compressive stress increases depending on the age of the specimens (Fig.6) and on the SF content [28, 29]. The effectiveness of steel fibers in enhancing compressive strength is strongly related to content, geometry and type of fibers. The relative resistance increase reaches, at 7 days of age, $11 \%, 21 \%$ and $29 \%$ for a SF content of $0.5 \%, 1 \%$ and $1.5 \%$, respectively (Fig.7). This observation is directly related to the mechanical adhesion performances of steel fibers within concrete which increase its ability to delay cracking development.

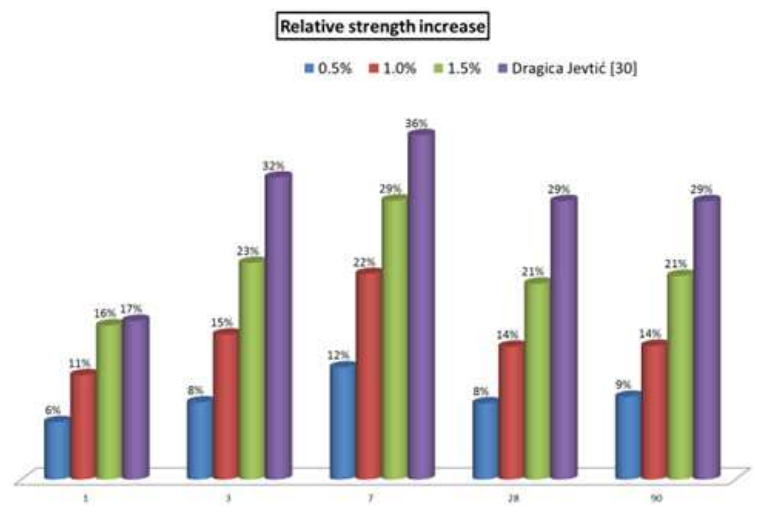

Figure 7: Relative stress - SF content (\%) evolutions.

discrepancy observed (Fig.8) at 7 days of age between the present results and those found in $[28,30]$ can probably be accounted for by the difference in both drying conditions and material types. Consequently, the effectiveness of SF materials in enhancing the compressive strength of concrete structures is confirmed. 


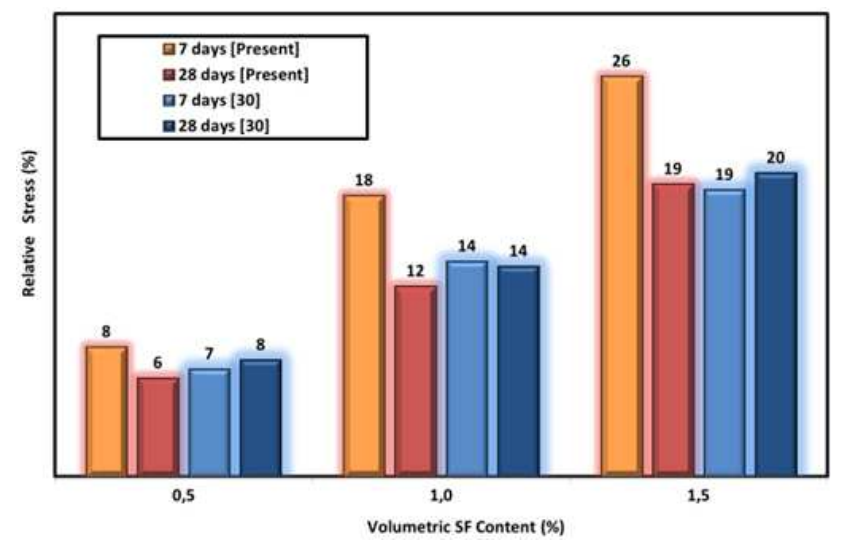

Figure 8: Relative stress - SF content (\%) evolutions.

However, we note that the relationship between compressive strength increase and SF content is linear (Fig.9).From these results and the discussions found in the literature, it appears that the quality and the type of steel fibers affect compressive stress performances of SFRC structures.

According to the graphical linear trend of Fig.9, it is advisable to propose a mathematical model, which can represent the relative extent of resistance by expressing variable staking both the quality and the volumetric content of steel fibers in concrete into account. The relationship between relative compression strength at 90 days of age and SF content appears to be linear (Fig.9), and the correlation parameter $\mathrm{R}^{2}$ is equal to 0.9 . This relationship, which is perfectly consistent with the results found in [29], can be expressed by (3):

$$
\sigma_{c, r e l}(\%)=100\left(\frac{\sigma_{s f r c}-\sigma_{c}}{\sigma_{c}}\right)=1+A \alpha_{s f} V_{s f}
$$

Where $\mathrm{A}=20, \sigma_{\mathrm{c}, \text { rel }}$ is the relative compressive stress, $\sigma_{\mathrm{SFRC}}$ is the compressive stress of the SFRC element, $\sigma_{\mathrm{c}}$ is the compressive stress of the non-SFRC element, $\mathrm{V}_{\mathrm{sf}}$ is the SF volumetric content and $\alpha_{\text {sf }}$ is a coefficient that describes the quality and type of the steel fiber.

For the SF presented in Figure 1, we consider $\alpha_{\mathrm{sf}}=0.6$. The coefficient $\alpha_{\mathrm{sf}}$ is used to characterize the type of steel fiber. For steel fibers of type "Novotex FE0730 $(1=30 \mathrm{~mm}$, $\mathrm{d}=0.7 \mathrm{~mm}$ )", $\alpha=1$ and for type "Dramix fiber RC65/35BN $(1=35 \mathrm{~mm}, \mathrm{~d}=0,55 \mathrm{~mm}) "$ fibers, $\alpha=0.5$ [29]. It must be noticed that the steel fibers of type "Dramix" similar in shape to the fibers studied here $(1=50 \mathrm{~mm}, d=0.75 \mathrm{~mm})$, while those of the "Novotex" type are different with hooks at both ends. Moreover, all three types have different tensile strengths $\left(f_{t}=1.9 \mathrm{GPa}\right.$ for the SF studied here, $\mathrm{f}_{\mathrm{t}}=$ 1.1 GPafor the "Dramix" ones and $f_{t}=1.15 \mathrm{GPa}$ for the

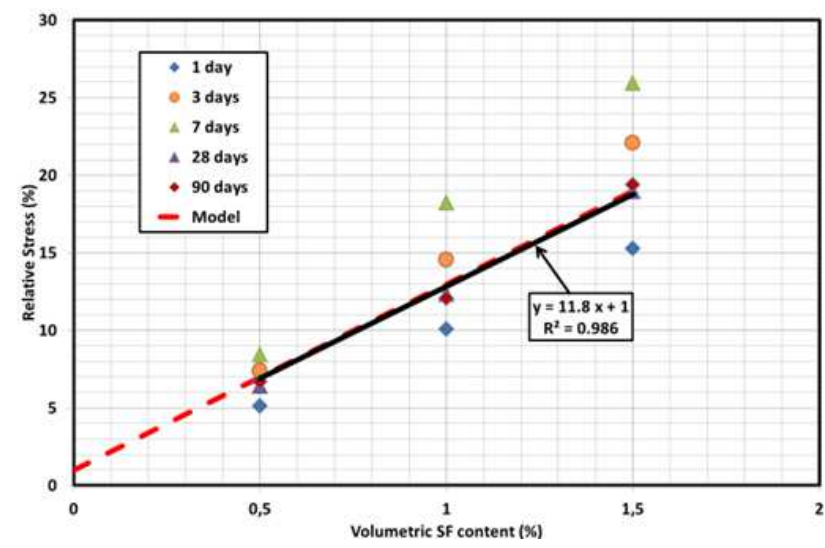

Figure 9: Relative stress - SF content (\%) evolutions.

"Novotex" ones.

The enhancement of the resistance of concrete containing steel fibers is also confirmed by the compression tests carried out on cylindrical specimens and by the bending tests carried out on prismatic specimens $(4 \times 4 \times 16$ $\left.\mathrm{cm}^{3}\right)$ [30].For steel fibers $(1 / \mathrm{d}=50)$ with a volumetric content of $0.45 \%$, strength can be improved by $17 \%$ at two days of age and approximately $29 \%$ at 90 days (Fig. 8). These results are higher than the results achieved experimentally here because the resistance of the concrete used in [30] is higher than that of the specimens used in the present study.

\subsection{Flexural Resistance}

The bending resistance of the $7 \times 7 \times 28 \mathrm{~cm}^{3}$ specimens is mainly affected by the adhesion characteristics of the steel fibers in the tensed parts of the concrete specimens. Adhesion depends on the quality, the type, and the geometrical characteristics (length, diameter, curvature, etc.) of the steel fibers. However, it appears that the strength of SFRC increases with time, and SF volumetric content (Fig. 10).Failure occurs in the form of brittle fracture for the plain concrete specimens and ductile fracture for the SFRC specimens (Fig.10). When the ultimate load is reached, the concrete matrix fails and the first crack appears on the beam specimen.

In all SFRC specimens, failure occurs at mid-span by pulling out of the steel fibers at maximum deflection and not by breaking up of the transverse sections.

For a SF content of $1.5 \%$, strength is significantly improved compared with the control specimen (1.5\% curve in Figs. 10 \& 11). Resistance tends toward a limiting value in relation to time. This value is, itself, an increasing function in terms of SF content (Fig. 11). 


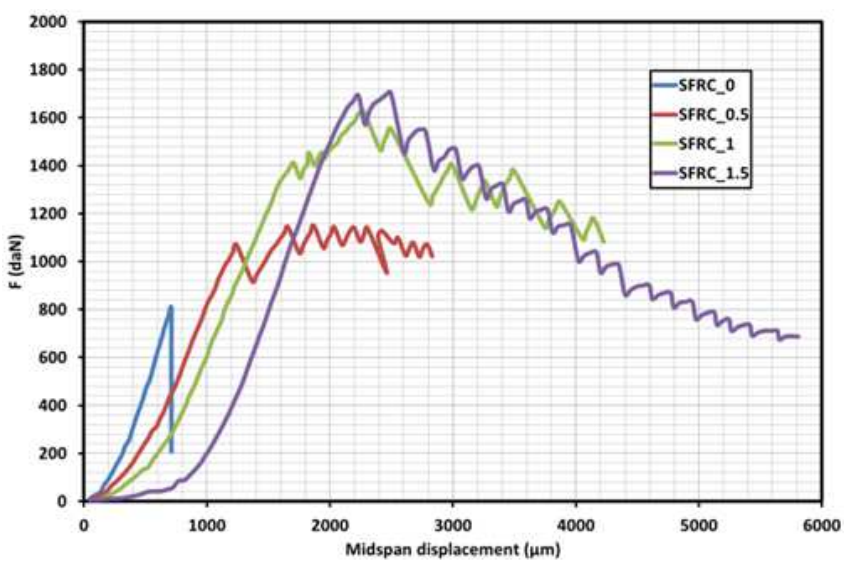

Figure 10: Force-midspan displacement evolutions.

For a volumetric content of $1.5 \%$, strength is enhanced by approximately $96 \%$, for SFRC specimens of 90 days age (Fig. 12). The enhanced extent obtained with a SF content of $0.5 \%$ is almost the same as that presented in [30] for a $0.45 \%$ content in different testing conditions (Fig. 12). For $1 \%$

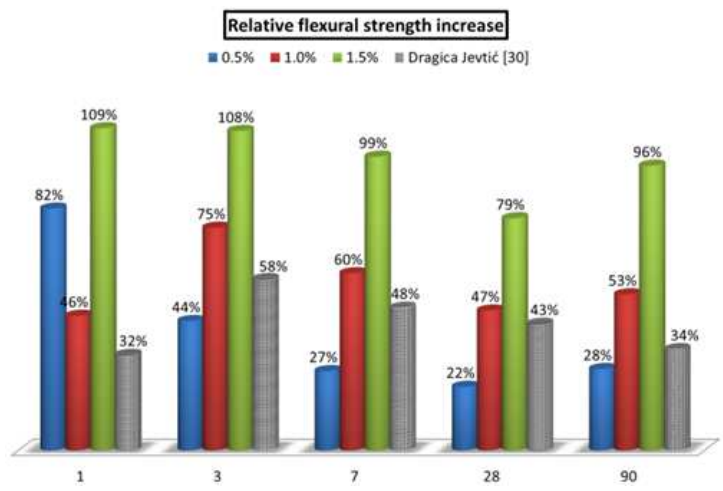

Figure 12: Relative flexural stress - age (day) evolutions.

The relationship between SFRC specimen real flexural stress and SF content do not appear directly linear. The relative strength of all the types of steel fibers found in the literature, on the other hand, increases linearly with increasing SF content $[28,29,30]$. However, this relationship is justified considering the present testing conditions and clarified by the relationships displayed in Figure 13. For the approximation of formula (3), the relative flexural strength can be represented by a linear mathematical equation written as (4):

$$
\sigma_{m, r e l}(\%)=100\left(\frac{\sigma_{m, s f r c}-\sigma_{m}}{\sigma_{m}}\right)=1+B \alpha_{s f} V_{s f}
$$

where $\mathrm{B}=113.3$ and $\alpha_{\mathrm{sf}}=0,6$ which characterizes the SF type; $\sigma_{\mathrm{m}, \mathrm{rel}}$ is the relative bending stress of the SFRC element; $\sigma_{\mathrm{m}, \mathrm{SFRC}}$ is the SFRC specimen bending stress and $\sigma_{\mathrm{m}}$ the bending stress of the non-SFRC elements.

Furthermore, the reliability of in service structures is closely linked to the ductility of the materials. The ductility factor is calculated from the average results according to

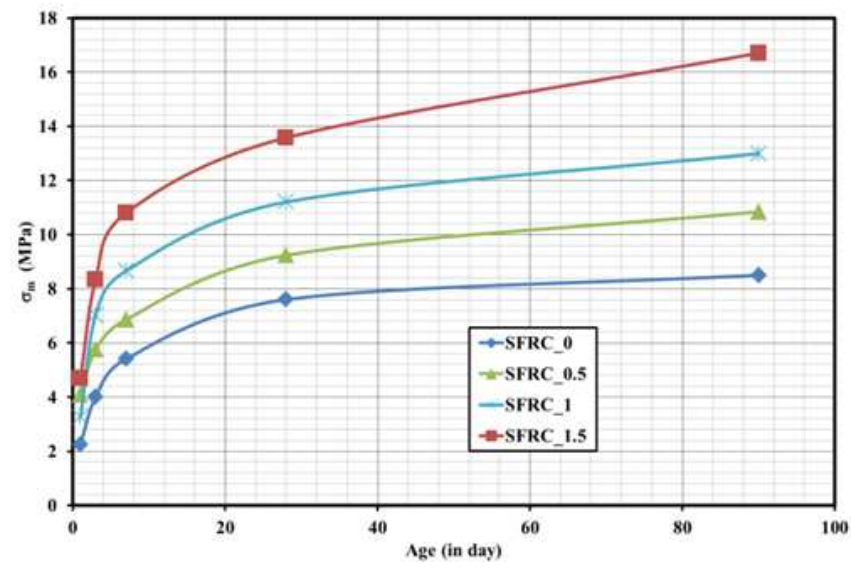

Figure 11: Flexural stress - age (day) evolutions.

SFRC specimens, the flexural strength is improved by $62 \%$. This improvement can be mostly attributed to the crackseaming and crack-arresting effects of SF elements.

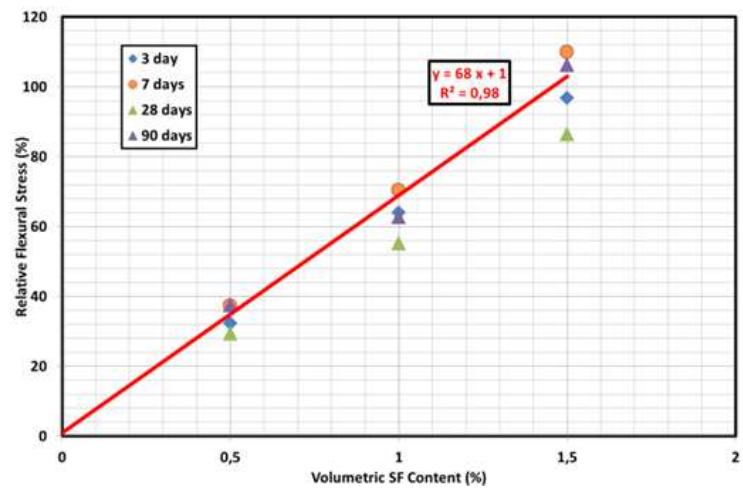

Figure 13: Relative flexural stress - SF content (\%) evolutions.

the recommendations of the technical standard [27] and presented as a function of SF content in Figure 14. This diagram shows that, right from a SF content of $1.5 \%$, specimen flexural performances, and consequently, reliability, are already enhanced by 2.33 in comparison with non-SFRC ones (Fig.14). The ductility factor can be used to highlight the quality of the steel fibers. It also depends on the quality of concrete and of the strength of the concrete/steel interface.

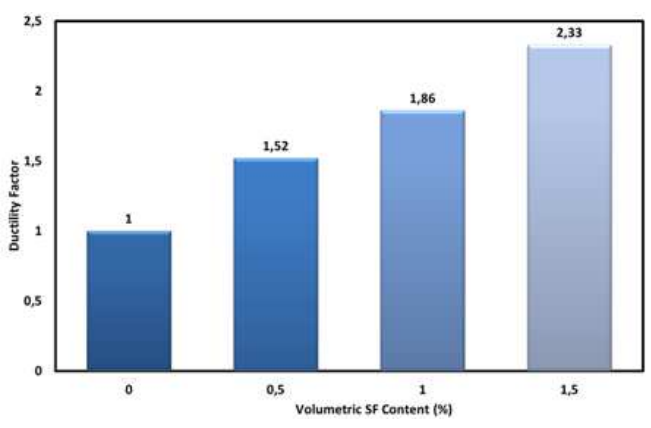

Figure 14: Ductility factor. 


\subsection{Abrasive Resistance}

Concrete and reinforced concrete structures endure variable and repeated loads, which may, in the end, induce material fatigue. Fatigue may, in turn, generate a progressive deterioration of the material up to failure, especially under applied complex mechanical loading cycles. High-performance of concrete materials, then, requires durability and resistance. This resistance can be expressed as the friction or abrasion bearing capacity of a material.

Abrasion resistance is studied experimentally through the weight (mass) loss of specimens resulting from abrasion testing. The testing equipment is the "micro Duval"

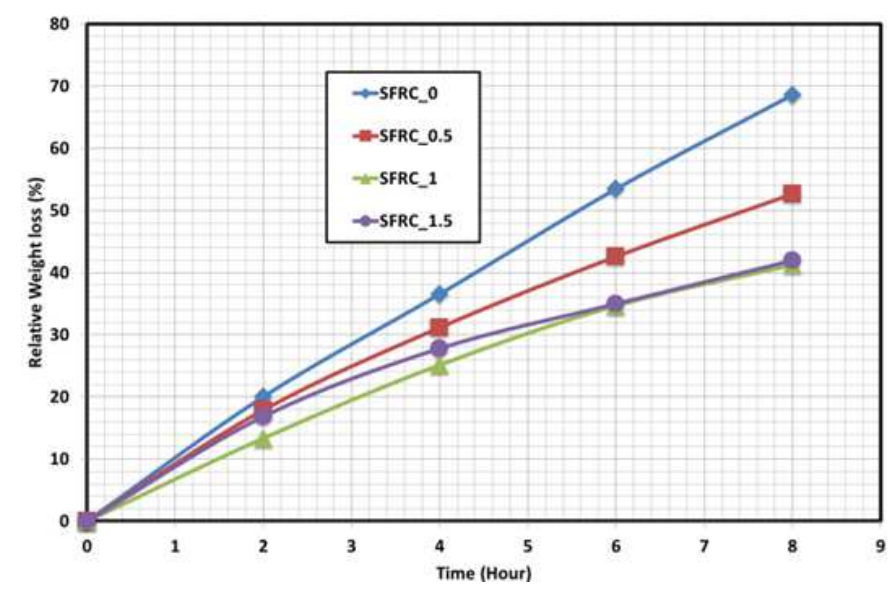

Figure 15: Abrasion weight loss-time evolutions.

Steel ball abrasion method is very aggressive at the beginning of the test. Skin concrete is abraded first but, as soon as abrasion reaches coarse aggregates, weight loss slows down. Differences in weight loss are directly visible to the naked eye on the shape of the specimens after the test It is interesting to note that not only do steel fibers reduce abrasion, but they also improve the consistency of the material matrix.

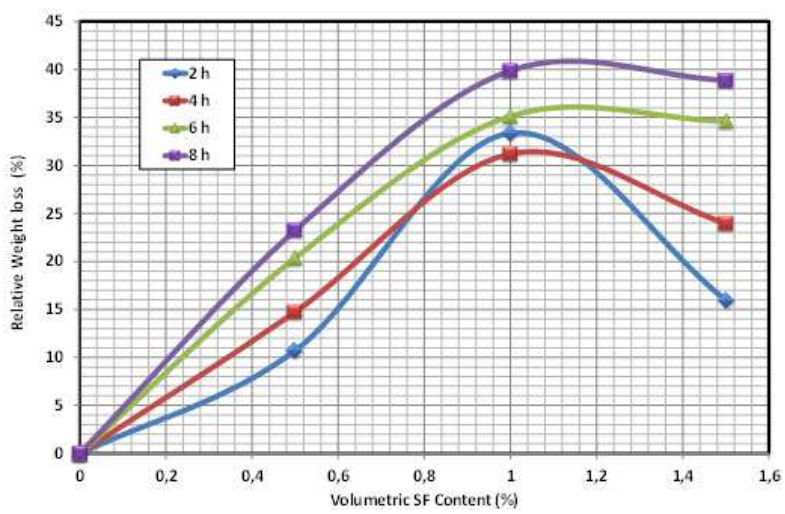

Figure 17 : Relative abrasive resistance-SF content.

The enhanced extent of abrasion resistance increases with time. For a SF content of $0.5 \%$ for instance, the resistance is improved by $10 \%, 14 \%, 20 \%$ and $23 \%$ after 2 , 4, 6 and 8 hours, respectively (Fig.15). However, we note machine (Figs.4\&5). The tested specimens are approximately the same weight and are subjected to the same abrasive load.

Figures 15 and 16 display the weight loss values of the different specimens tested at 28 days of age. It can be seen that the abrasion resistance of the specimens containing SF elements is remarkably improved and increases with the increase in SF content. The plain concrete control specimen (SFRC_0) degradation is almost linear according to abrasion time (Fig.15) whereas it decreases, for the SFRC specimens according to the SF volumetric content (Fig.16).

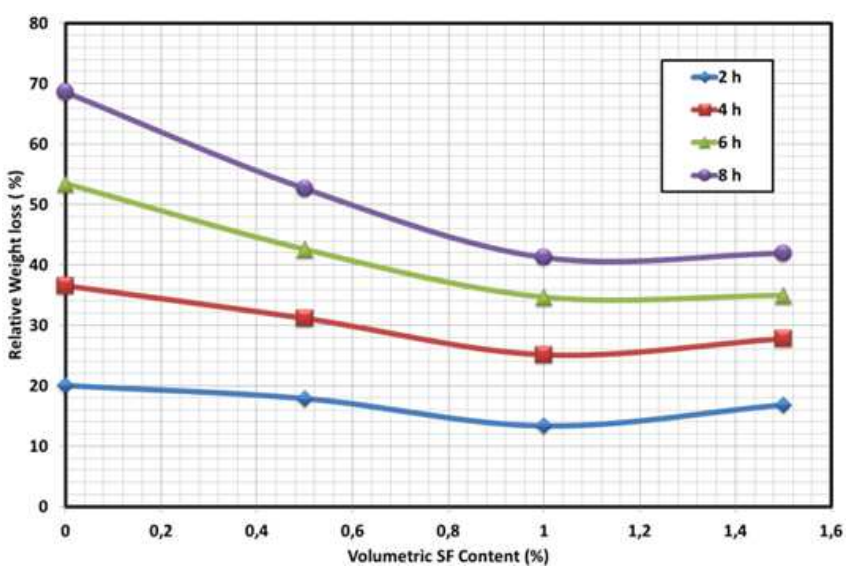

Figure 16: Abrasion weight loss-SF content (\%) evolutions.

that the optimum volumetric content to reduce abrasion impact is about $1 \%$ (Figs. $16 \& 17$ ). Beyond this value, the relative weight loss remains constant or even decreases slightly with increasing content (Fig.17).

If this observation is very important for construction engineering, it, however, remains limited to the materials and testing conditions used here. A survey of the literature reveals that a considerable amount of effort has been devoted to the study of the abrasion resistance of reinforced concrete with, however, different testing conditions (type of fibers, unique SF content, device, etc.) [31, 32, 33, 34]. None of them, nevertheless, has underlined the importance of the SF volumetric content.

\subsection{Relationships between Abrasive, Compressive and Flexural Strengths}

The abrasion resistance of SFRC is often related to toughness, which can be expressed in terms of flexural and compressive resistance [31, 32, 33]. Steel fibers, indeed, can reduce the porosity of the material and increase the adhesion between the different components of the SFRC material matrix. Consequently, concrete specimens are more resistant to mechanical abrasion.

Measurements have been carried out after $2 \mathrm{~h}, 4 \mathrm{~h}, 6 \mathrm{~h}$ and $8 \mathrm{~h}$ of abrasion. The relationship between the weight loss of the SFRC specimens at 28 days of age and their 
compressive and flexural resistance is decreasing linearly (Figs. 18 \& 19). The correlation coefficient, $\mathrm{R}^{2}$, used for the mathematical identification of the measurement points, is higher than 0.5 , save after the 2-hour abrasion time, for which result scattering is high and $\mathrm{R}^{2} \cong 0,4$ (Figs.18 \& 19).

Similarly, we can see that the abrasion resistance of the tested SFRC specimens is proportional to both flexural and compressive resistances and depends on the abrasion

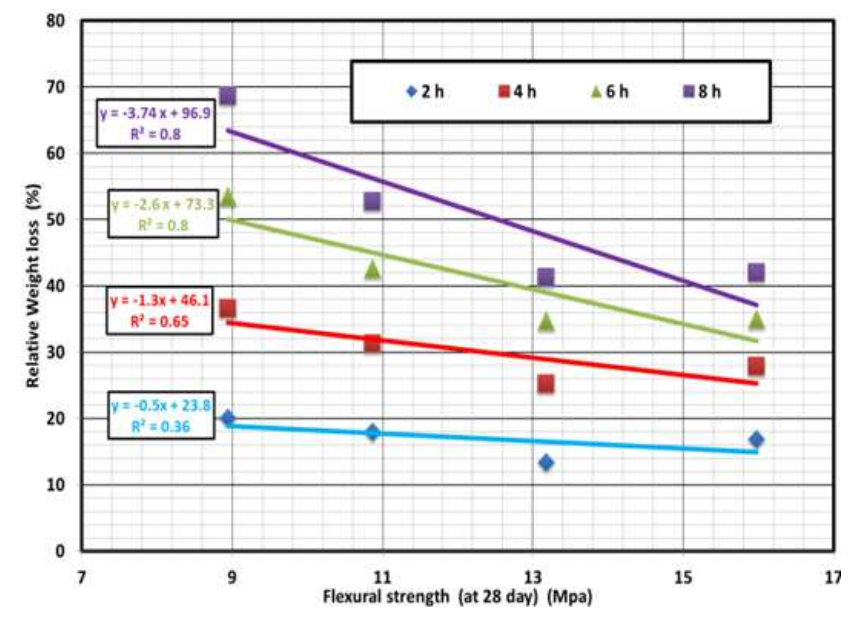

Figure 18: Abrasion vs. flexural resistance.

\section{Conclusions}

The purpose of this article was to quantify the effects of the addition of SF elements within ordinary concrete specimens by examining their mechanical properties including compressive, flexural and abrasion resistance. The study shows that compressive strength increases with time for the optimum SF content of $1.5 \%$. The effectiveness of SF in enhancing compressive strength depends on the content, the geometry and the type of steel fibers. The enhanced extent is maximum at 7 days of age and stabilizes after 28 days at a relative value within the range $10-20 \%$.

The SFRC bending strength increases with time. The addition of SF considerably improves bending resistance, which doubles with a SF content of $1.5 \%$. Ductility, which is linked to the mechanical behavior of the tested specimens as regards flexion, also increases. This improved property helps prevent SFRC brittle fracture under bending stress. The presence of SF in concrete allows for the reduction of the material porosity and increases the adhesion of the material matrix. Both are involved in the significant increase in the ductility of the specimens and in the reduction of cracking initiation.

Steel fibers also increase the abrasion resistance of SFRC materials. The optimal SF content to reduce the effect of abrasion is close to $1 \%$. The relationship between the weight loss of the SFRC specimens at 28 days of age and their compressive and flexural resistance is decreasing linearly. So the abrasion resistance of SFRC is highly dependent on their compressive and flexural resistance. exposure time. The relative weight loss of the different specimens is higher on the 8th hour of the abrasion test (Figs. 18 \& 19).

These relationships are almost the same trend as those presented in related previous studies conducted on both steel and polypropylene fibers [31, 34]. The results, however, are given according to the abrasive speed, $E_{R}$ ( $\mathrm{g} / \mathrm{min}$ ) and for a unique abrasion exposure time.

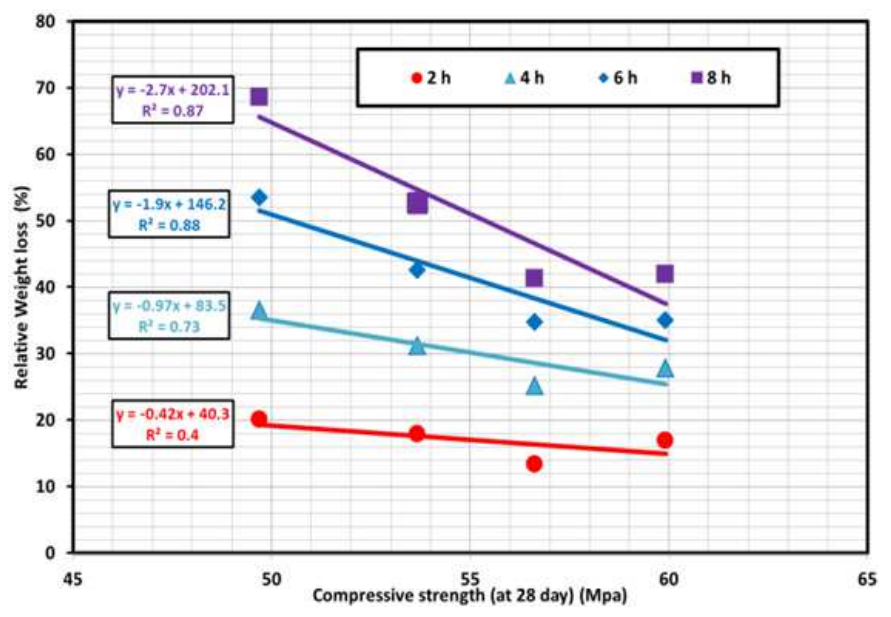

Figure 19: Abrasion vs. compressive resistance.

\section{References}

[1] Rossi, P., 1998. Les bétons de fibresmétalliques. Presse de l'ENPC.

[2] Serna Ros P., (1984), "Etude de la contribution des fibresmétalliques à l'amélioration du comportement du béton au cisaillement", Thèse à l'ENPC, 1984, 77 p.

[3] Fanella D., Naaman A.E., (1985), "Stress-Strain Properties of Fiber Reinforced Mortar in Compression", ACI Materials Journal, vol. 82, n 4 , 1985, pp. 475-483.

[4] Soroushian P., Lee C.-D., (1990), "Tensile strength of steel fiber reinforced concrete. Correlation with some measures of fiber spacing", ACI materials Journal, vol. 87, nº 6,1990 , pp. 541-546.

[5] Balaguru P., Dipsia M.G., (1993), "Properties of fiber reinforced high-strength semi-lightweight concrete", $A C I$ Materials Journal, vol. 90, n5, 1993, pp. 399-405.

[6] Ramakrishnan V., Coyle W.V., Kulandaisamy V., Schrader E.K., (1981), "Performance Characteristics of Fiber Reinforced Concretes with Low Fiber Contents", ACI Materials Journal, vol. 78, n 5 , 1981, pp. 388-394.

[7] Harrouche N., (1989), "Formulation etcomportement à la fissuration des fibresmétalliques", thèse de Doctorat, Université Paris 6, 1989.

[8] Paillere A.M., (1993), "Le béton de fibresmétalliques, Etatsactuels des connaissances", Annales de l'ITBTP, sériebéton, 302, 1993, n 515, pp. 39-68.

[9] Gopalaratman, V.S., and Shah S.P., 1985. Softening Response of Plain Concrete in Direct Tension. ACI Journal, 
82(3), 310-323.

[10] Damgir, R.M., and Ghugal, Y. M., 2010. Prediction of compressive strength by incorporating steel fibers, 35th Conference on Our World in Concrete \& Structures, Singapore, 25 - 27.

[11] Zollo R.F, (1980), "Fibrous concrete flexural testingDeveloping standardized techniques", ACI Materials Journal, vol. $77, \mathrm{n}^{\circ} 5,1980$, pp.363-368.

[12] Atassi M.F., (1997), "Etude du comportement des bétons de fibresmétalliques : influence de la géométrie des fibres, du dosage et de l'anisotropie de leurrépartition", Thèse de l'INSA de Lyon, 1997, 222 p.

[13] Daniel L., (2001), "Comportement de poutres en béton à hautes performances fibré sous sollicitationssismiques", Thèse de Doctorat, Université de Nantes, 2001, 143 p.

[14] Dupont D., Vandewalle L., (2005), "Distribution of steel fibres in rectangular sections", Cement and Concrete Composites, vol. 27, n³, 2005, pp. 391-398.

[15] S. ROLS, Conception d'un composite ciment-fibres de polypropylène ductile et durable, ThèseGénie des matériaux. Lyon : INSA, 1996, 206p.

[16] Casanova, P., bétons renforcés de fibresmétalliques du matériau a la structure Etude expérimentaleetanalyse du comportement de poutressoumises à la flexion et à l'efforttranchant, ThèseDoctorat, EcoleNationale des Ponts et Chaussées, 1995, 225 pages.

[17] N. Banthia, M. Sappakittipakom.Toughness enhancement in steel fiber reinforced concrete through fiber hybridization. Cement and concrete research. 37 (2007) 1366- 1372.

[18] M. Bentalha, H. Houari. Etude du comportement des matrices cimentairesrenforcées defibresmétalliques sous chargement monotonecroissant. Sciences \&Technologie. 25(2007) 51-58.

[19] Metha, P. K. \&GerwickJr, B. C. (1982). Cracking-Corrosion Interaction in Concrete Exposed to Marine Environment. Concrete International. v. 10, p. 45-51

[20] Mehta, P. K. \&Monteiro, P. J. M. (2006). Concrete: microstructure, properties and materials, McGraw-Hill, Columbus, USA

[21] HU.XG.Momber, AW.YinYG; Hydro-abrasive erosion of steel fibre reinforced hydraulique concrete Wear; $2002: 253: 848-54$.

[22] R. Nilica, H. Harmuth.; Mechanical and fracture mechanical characterization of building materials used for external insulation composite systems. Cement and Concrete Research, 35(2007) 1641-1645.

[23] Nicholas, J. P., 2002. Abrasion wear, abrasion resistance, and related strength characteristics in concrete, with special reference to concrete pavers. Thesis $(\mathrm{PhD})$. University of the Witwatersrand. Johannesburg

[24] NFEN12390-1(2003),normeeuropéenne,Essai pourbétondurci,Partie1 :Forme, dimensions et autresexigences relatives aux éprouvettes et aux moules,Octobre 2001.

[25] NFEN12390-3(2003),normeeuropéenne,Essai pourbétondurci,Partie3:Résistanceàla compressiondes éprouvettes, 2003.

[26] NFEN12390-5,Essai pour bétondurci, Partie5 : Résistance à la flexion suréprouvettes, Octobre 2001.

[27] P18-409 (avril 1993) NormeFrançaiseafnor 1993. Béton avec fibresmétalliques. Essai de flexion.

[28] RM Damgir, Y M Ghugal,; PREDICTION OF COMPRESSIVE STRENGTH BY INCORPORATING STEEL FIBERS ; $35^{\text {th }}$ Conference on OUR WORLD IN CONCRETE \& STRUCTURES: 25 - 27 August 2010, Singapore (Article Online Id: 100035028);

[29] Dhakal, R.P., Wang, C., Mander, J.B. (2005) Behavior of steel fibre reinforced concrete in compression. Nanjing: International Symposium on Innovation \& Sustainability of Structures in Civil Engineering, Nov 2005.

[30] Dragica Jevtić, Dimitrije Zakić, Aleksandar Savić; MODELING OF PROPERTIES OF FIBER REINFORCED CEMENT COMPOSITES; Architecture and Civil Engineering Vol. 6, No 2, 2008, pp. 165 - 172; DOI:10.2298/FUACE0802165J.

[31] Zoran J. Grdica,Gordana A. ToplicicCurcic a, Nenad S. Ristic a, Iva M. Despotovic b;Abrasion resistance of concrete micro-reinforced with polypropylene fibers;http://dx.doi.org/10.1016/j.conbuildmat.2011.07.044.

[32] Yu-Wen Liu, Tsong Yen, Tsao-Hua Hsu; Abrasion erosion of concrete by water-borne sand; Cement and Concrete Research 36 (2006) 1814-1820.

[33] Hui Li *, Mao-hua Zhang, Jin-ping Ou ; Abrasion resistance of concrete containing nano-particles for pavement; Wear 260 (2006) 1262-1266.

[34] Rafat Siddique ,Kushal Kapoor, El-Hadj Kadri, Rachid Bennacer; Effect of polyester fibres on the compressive strength and abrasion resistance of HVFA concrete; http://dx.doi.org/10.1016/j.conbuildmat.2011.09.011 